The effectiveness of trauma healing methods to reduce Post-Traumatic Stress Disorder (PTSD) on teenage victims of Mount Merapi eruption

\author{
Tentama, Fatwa $\$ \\ University of Ahmad Dahlan, Indonesia (fatwa_ten10@yahoo.com) \\ Mulasari, Surahma Asti \\ University of Ahmad Dahlan, Indonesia (rahmasti_fkmuad@yahoo.com) \\ Sukesi, Tri Wahyuni \\ University of Ahmad Dahlan, Indonesia (yons_by@yahoo.com) \\ Haryono, Widodo \\ University of Ahmad Dahlan, Indonesia (widodohariyono@yahoo.com)
}

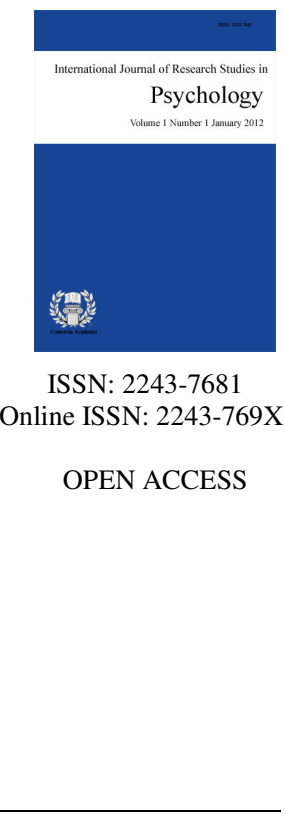

\title{
Abstract
}

Mount Merapi eruption in 2010 is categorized as the largest eruption during the last 20 years. The effect of the eruption caused not only many casualties, environmental damage, but also deep trauma to the residents living on the slopes of the mountain, especially the teenagers. The design of the applied experiment was a pre-test post-test control group design. It is a design of experiment involving two group i.e. experimental and control in which the target behaviour of the subjects is measured before and after the experimental treatment given. The result of t-test analysis namely independent sample t-test in the experimental and control group using gain score indicates that there is different mean between the experimental group and the control group. The result of t-test analysis shows $\mathrm{t}=1.925$ and $p=0.059$ (sig. 2-tailed), 0.0295 (sig 1-tailed) ( $p<0.05)$. Therefore, it is significant. It means there is a significant difference in Post-Traumatic Stress Disorder (PTSD) between the experimental group and the control one. The experimental group has a lower rate of PTSD compared with the control group. It can be concluded that trauma healing methods are effective to reduce PTSD.

Keywords: PTSD; trauma healing; teenage victims 


\section{The effectiveness of trauma healing methods to reduce Post-Traumatic Stress Disorder (PTSD) on teenage victims of Mount Merapi eruption}

\section{Introduction}

On October 25, 2010 mount Merapi which lies on the border between Central Java and Yogyakarta, Indonesia erupted. It caused hundreds of people died. Currently, the remains of the eruption are the survivors who have lost their family and their beloved relatives, shelters as well as properties owned (cattles, rice fields, clothes, vehicles etc.). Besides, public economic activities became paralyzed, people lost their jobs to fulfil their daily needs such as farming, husbandry, teaching in schools, and working in local government offices. The eruption of mount Merapi in 2010 caused a lot of damage, loss and victims (Andayani, 2011). It also gave negative impacts. One of them is psychological trauma for the survivors.

According to Taylor (2000) some conditions that can potentially be traumatic events are disaster, victims of crime, loss of the loved ones (family, relatives, friends, etc.), and loss of properties. Trauma in psychological term shows shock condition and stress by an event which remains long in the victim's memory. The result of the survey shows that $20 \%$ of individuals who undergo traumatic event will suffer Post-Traumatic Stress Disorder (Van Etten \& Taylor, 1998). Boulware (1999) explains that traumatic event triggers psychological disorders. If the disorder appears before a month, it is called acute stress disorder while if it occurs after a month it is called Post-Traumatic Stress Disorder (Terr, 1988). Acute stress disorder (ASD) is a maladaptive reaction that occurs in the first month after a traumatic experience undergone while Post-Traumatic Stress Disorder (PTSD) is an ongoing maladaptive reaction to a traumatic experience. ASD is a major risk factor for PTSD, because many people with ASD later suffer PTSD (Bryant et al, 2000). PTSD is re-experiencing very traumatic event which can be noticed by the increase of stimulation and avoidance associated with the event. PTSD usually lasts for months, years or even some decades and the reaction may appear after several months or years after there is exposure to a traumatic event (Zlotnick et al., 2001).

Post-traumatic stress is a stress that occurs after the event of trauma (Rothschild, 2000). Traumatic event leads to post traumatic stress disorder especially severe distress which can be undergone by almost everyone. It usually occurs all of a sudden and the subjects accept it as something harmful for them and others. Besides, they are not able to respond properly (Schiraldi, 2009). Kaplan and Sadock (1997) explain that Post-Traumatic Stress Disorder is as a deep emotional stress which can happen to almost everyone who undergoes traumatic events. According to Durand and Barlow (2006) Post-Traumatic Stress Disorder is an emotional disorder that causes permanent distress. It occurs after the individuals face the threatening situation that makes them feel totally helpless or frightened. The victims feel that they re-experience the trauma so they avoid the stimuli associated with it, numb responsivity and have a level of alertness and increased arousal.

The reaction of Post-Traumatic Stress Disorder appears when individuals experience the intense psychological pressure coming from the source of pressure beyond the ordinary experience undergone or what so called the extreme stressor (Ranimpi, 2003). Extreme stressor includes severe accident or catastrophe, rape or crimes with violence, war, sexual abuse in children, watching traumatic events, and sudden death of the beloved persons (Foa et al, 1999). The negative impacts may occur to people with Post-Traumatic Stress Disorder are bad temper, loss of concentration, loss of interest in interacting with the environment, insomnia, feelings of being alienated from others, and having nightmares. If Post-Traumatic Stress Disorder is undetected and untreated, it can lead to permanently serious medical and psychological compilation that can eventually interfere the social life and working life of the victims (Flannery, 1999). Paton (2009) also states that individuals who undergo traumatic events are less capable to express their feelings so that it enables them to have emotional problems. After the traumatic events, there are two distinct phases. The first is an initial disturbance when the protection is damaged by trauma so that dysfunction may occur. The second, they feel close to death. Subjects often feel 
The effectiveness of trauma healing methods to reduce PTSD on teenage victims of Mount Merapi eruption

confused and do not know what happens. It is what so-called dissociation (Curnow, Rick, \& Adelaide, 2007).

PTSD symptoms appear soon after traumatic event. There are four types of symptoms namely: (1) life returning/re-experiencing, (2) avoidance, (3) emotional numbness, and (4) a feeling of tension (arousal/hyper-arousal) (Foa et al., 2000). APA (1994) describes the symptoms of Post-Traumatic Stress Disorder as seeing a traumatic event or re-experiencing, avoidance, hyper-arousal. Those symptons will appear after the incident take place more than a month. According to the criteria of DSM IV (1994), Post-Traumatic Stress Disorder is divided into acute experienced disorder (the symptom lasts for less than three months), chronic experienced disorder (the symptom lasts for three months or more), and the disruption experienced disorder. The last is the onset of symptom which appears six months or more after stressful events occur. Nevid et al. (2005) defines Post-Traumatic Stress Disorder as an ongoing maladaptive reaction to a traumatic event. This type of disorder can be found at soldiers on the battlefield, victims of rape, victims of accident, they who become the witnesses of home and environment destruction by natural disasters such as floods, earthquakes, tornadoes, and technological disasters.

There were many trauma healing techniques or methods which could be applied to the victims of Mount Merapi eruption who had PTSD. This research implemented five methods namely visualization, pal and gum, tai chi, acupressure, and massage accompanied by Javanese traditional music. Training modules of trauma healing methods used refers to the manual of CAPACITAR Trauma Recovery and Transformation written by Patricia Mathes Cane (2011, YABES Foundation). It consists of 5 methods or sessions.

$>\quad$ The first method is visualization. Visualization is given through hand movement and touching for listening to our body. Although we get stressed and life difficulties, we have ability to nurture ourselves, to calm and relax our soul and bodies. Listening to our body means learning to feel what is happening at the moment. The next stages of visualization can be seen in the module.

$>\quad$ The second is Pal and Gum method. In this method, there are eight exercises to balance and enhance our body's energy and to eliminate the tension. They are very useful and appropriate for individuals who get stressed due to trauma. The detail stages can be seen in the module.

> The third is Tai Chisarana. It is stress and trauma healing that brings balance and harmony of body, mind and spirit. Tai Chi is able to build stamina and strength which is often lost in individuals who get trauma. The detail stages of this method can be seen in the module.

$>\quad$ The fourth is accupressure method. This method uses finger pressure on specific points to open life energy blockages in our body. The result of the research revealed acupressure could help effectively lose the symptoms of stress due to trauma such as restlessness, anxiety, insomnia, abdominal pain, headache, and pain all over the body. Acupressure points can be used when the symptoms of trauma and stress appear or if it is practiced every day it can maintain smooth flow and the balance of energy to the entire body to prevent the symptoms of stress. The detail stages can be seen in the module.

$>\quad$ The fifth is massaging method. One of the effects of stress due to trauma is having strong feeling or emotions. The emotion flows through our bodies such as feeling of afraid, angry, anxious, sad etc. How to cope with raging emotion is by admitting it and doing something to free the energy blockage and balance the energy from the emotion. One way to release the blockage and balance the energy is by having massage techniques on fingers, shoulders, neck, head, etc. Massage stimulates the body's energy to flow smoothly, become healthy and balance all systems in the body. The detail stages can be seen in the module.

The previous studies conducted by experts have found many interventions to overcome PTSD. One of them is cognitive-behavioral therapy (CBT). It is a type of therapy that effectively prove to cope with PTSD. The effectiveness of cognitive-behavioral therapy in handling PTSD is proven by two strong methodologically 
clinical test in empowering raped-women (Foa et al., 1991). Besides cognitive-behavioral therapy (CBT), according to Heights and Chilcote (2007), art therapy especially drawing is also quite effective in reducing Post-Traumatic Stress Disorder. Art therapy is psychologically beneficial and culturally can be applied as an intervention for children. Children are readier to share the trauma experienced in which they previously find it difficult to express. There are also some other types of interventions such as exposure therapy, eye movement desensitization and processing (EMDR), psychological debriefing (PD), and drugs, which prove to be effective to cope with Post-Traumatic Stress Disorder (PTSD). These kinds of interventions also have been studied using experimental and statistical methods. Nowadays, there is clinical and scientific knowledge about what treatment modalities to help patients with post-traumatic problems (Foa et al.). This study is aimed to test whether trauma healing methods such as visualization, pal and gum, tai chi, acupressure, and massage accompanied by Javanese traditional music with Capacitar approach can effectively reduce Post-Traumatic Stress Disorder to teenagers i.e. the students of SMP Negeri (state junior high school) 1 Turi, Sleman, Yogyakarta, Indonesia as the victims of Mount Merapi eruption.

The implications of this study for students and teachers is a method of trauma healing role in providing skills in trauma healing methods practiced on the teachers and students and can help to reduce Post-Traumatic Stress Disorder experienced by the students victims of Mount Merapi eruption.

\section{Method}

\subsection{Research Subjects}

The determination of the sample is without randomization. It is employed because a pure experimental design is not possible to be implemented (Mayers, 2002). The subjects in this study were male and female students of SMP Negeri 1 (State junior high school 1) Turi, Sleman, Yogyakarta, Indonesia. There were 60 students as the participants who were divided into control group and experimental group. Each group consisted of 30 students. In this study, the selection of the subjects was non-randomized. It was selected based on certain defined characteristics of the subjects such as experiencing trauma after the eruption of Mount Merapi; directly experiencing the catastrophic event of the eruption and living in the area which was directly affected by the eruption.

\subsection{The Measurement}

Post-Traumatic Stress Disorder scale would be revealed by using a scale which was developed by researchers refering to the theory of Diagnostic and Statistical Manual of Mental Disorder (DSM-IV, 1994) and the Sidran Traumatic Stress Foundation (2003). The scale was arranged based on the aspects set out in the diagnostic and Statistical Manual of Mental Disorder (DSM-IV, 1994) and the Sidran Traumatic Stress Foundation (2003), namely:

A. Intrusive Re-experiencing: traumatic events which recur in memory.

B. Avoidance: avoidance towards something related to trauma and a broken feeling.

C. Arousal: excessive awareness (hyper-arousal).

\subsection{Validity and Reliability Measurement}

The items in the completed scale then were selected based on the criteria of coefficient correlation of the corrected total item $\left(\mathrm{r}_{\mathrm{xy}}\right)$. Post-Traumatic Stress Disorder scale used limit 0.3 so that the items which had different index greater than or equal to 0.3 deserved to be included in the scale of the research. The scale of Post-Traumatic Stress Disorder became 23 items. It is valid with the coefficient correlation of the lowest total items 0.307 and the coefficient correlation of the highest total items 0.735 . Reliability testing on the 
The effectiveness of trauma healing methods to reduce PTSD on teenage victims of Mount Merapi eruption

Post-Traumatic Stress Disorder scale used formula alpha $(\alpha)$ of Cronbach. It only included valid items. The Scale of Post-Traumatic Stress Disorder had a reliability coefficient of 0.909. Thus, the instrument was reliable and it could be used as a data collection instrument in this research. The Scale of Post-Traumatic Stress Disorder consists of three aspects, namely, intrusive re-experiencing with the example of items such as "I get a nightmare about mount Merapi eruption", avoidance for example in "I avoid talking about Mount Merapi eruption", and arousal aspect such as "I get shocked easily."

\subsection{Research Design}

This type of research is quasi-experimental. It is an experiment in which the control of the extra variables is not so tight, and the determination of the sample is without randomization. It is employed because a pure experimental design is not possible to be implemented (Mayers, 2002). The design of the experiment used was pre-test post-test with control group design. It is a design of experiments using two groups, experimental and control group in which the target behavior of the subjects were measured before and after the experimental treatments were given.

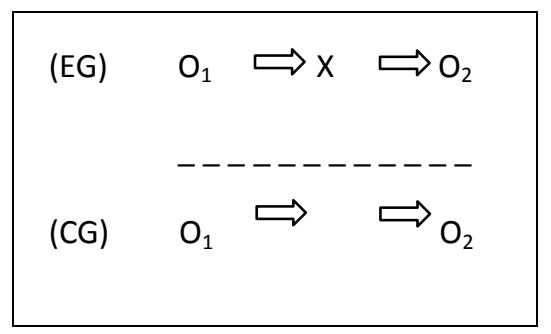

Figure 1. Experiment Design

Description:

$\mathrm{EG}=$ Experimental Group

$\mathrm{CG}=$ Control Group

$\mathrm{O}_{1} \quad=$ Initial measurements prior trauma healing methods given (pretest)

$\mathrm{X}=$ Provision of trauma healing method

$\mathrm{O}_{2} \quad$ = Final measurement after trauma healing methods is given (posttest)

In this research design, the changes occured after the intervention were recorded and compared with the situation before the intervention. Pre-test was executed before trauma healing methods treatment was given. After the trauma healing training was done, the post test then was given. The different result between pre-test and post-test was assumed as the effect of the experiment or the treatment given (Arikunto, 2010). Pretest informed initial position of the subjects prior to treatment given. Constancy occured because the score of VT was the score of the post test results which was subtracted from the results of a pretest of each subject. So the scores obtained were the increase or decrease of VT due to the treatment given (Robinson in Seniati, L.dkk. 2011). The result of pretest and post-test in each group was then compared to determine the level of trauma of the students to know the effectiveness of the trauma healing method in decreasing the trauma (PTSD) of the students.

\subsection{The Instrument and Materials of the Research}

The instruments used in this study:
A. The scale of Post-Traumatic Stress Disorder
B. Hand-out of the material
C. Room or place for holding the training
D. Audio-visual equipment i.e. laptops, LCD, mix, speakers 
Tentama, F., Mulasari, S. A., Sukesi, T. W., \& Haryono, W.
E. Video and musical instrument for relaxation
F. Camcorders and camera

\subsection{The Procedure of the Experiment}

The research was conducted in three phases namely preparing the research, implementing the research and constructing the research reports. As the early stage of preparation, the researchers conducted field surveys for two months through observations and interviews with students and teachers, especially counseling teachers. Then, they conducted a literature study based on the observations, interviews and field findings. After that, they constructed and made a research proposal. Before conducting the research, researchers constructed a research instrument measurement i.e. Post-Traumatic Stress Disorder scale. This scale would be used as a measurement or research scale. The final stage of the preparation in this study was having a letter of permission to do the research in Sleman regency government through regional planning agency.

In this study, there were some activities carried out such as coordination with the principal for conducting the research, then with the counseling teachers and teachers in charge to organize and conditionalize the students. The early stage of the study was to run a trial of Post-Traumatic Stress Disorder scale in order to get valid and reliable research scale. The scale consisted of 42 items and it was given to 30 students as the subjects of the trial. It was held on 18 November 2011. After the result data were gained, they were analyzed by SPSS 17.0. The students who were selected based on specified characteristics were divided into two groups i.e. an experimental and a control group. The experimental group was a group that would be treated by using trauma healing methods while the control one was with no treatment. Each group consisted of 30 subjects. However, during the study there were some students who withdrew or had a permission due to such illnesses. The research began with the division of the research scale which had been prepared (pretest). It was given to the experimental and control group. Before the scale was distributed, students were given an explanation about the procedures of filling the scale by researchers assisted by teachers in charge. The research was continued by implementing trauma healing methods guided by researchers/instructors of the trauma healing. It was held for two days, 29-30 November 2011. At this stage there were several methods of trauma healing which were divided into 5 sessions to be given to the experimental group.

Session 1. Visualization method.

It is given through movement and hand touching to listen to our body. Facing the stress and difficulties of this life, we have ability to nurture ourselves, to calm and to relax our soul and body. Listening to our body means learning to feel what is happening at the moment. The detail stages can be seen in the module.

Session 2. Pal and Gum method.

There are 8 exercises to balance and enhance our body's energy and to eliminate tension. This method is very useful and appropriate for individuals experiencing stress due to trauma. The detail stages are explained in the module.

\section{Session 3. Tai Chi method}

Tai Chi is a means of healing stress and trauma that brings balance and harmony of the body-mind-spirit. Tai Chi is able to make stamina and strength which is often lost in individuals who experience trauma. The detail stages can be seen in the module.

Session 4. Acupressure method.

This method uses finger pressure on specific points to open energy blockages in our body. The research revealed that accupressure can help effectively lose the symptoms of stress due to trauma such as restlessness, anxiety, insomnia, abdominal pain, headache, and pain all over the body. Acupressure points can be used when 
The effectiveness of trauma healing methods to reduce PTSD on teenage victims of Mount Merapi eruption

the symptoms of trauma and stress appear. When it is practiced every day, it is to maintain the smooth flow and the balance of energy to the entire body to prevent the symptoms of stress that might arise.

Session 5. Massaging method.

One of the effects of stress due to trauma is having strong feeling or emotion. It flows through our body in such feeling like being afraid, angry, anxious, sad etc. How to cope with raging emotion is by recognizing it and doing such activities to free the blockage of energy from emotion. One way to release energy blockages and to balance the energy from the raging emotion is by having massage techniques on fingers, shoulders, neck, head, etc. Massage stimulates the energy to flow smoothly and healthily and balances all the systems in the body. The detail stages are described in the module.

\subsection{Data Analysis}

This research used parametric statistical methods. The analysis technique used in this study is the t-test: independent sample t-test and paired sample t-test. Independent sample t-test was used to test whether there is any difference in the level of Post-Traumatic Stress Disorder between the experimental group and the control group and using paired sample t-test to determine whether there is any difference in the level of Post-Traumatic Stress Disorder between before and after treatment in the experimental group. The entire data computation performed with SPSS for Windows 17.00.

\section{Result}

The result of t-test analysis i.e. the paired sample t-test in the experimental group shows that the trauma healing method has positive effect in reducing Post-Traumatic Stress Disorder (PTSD). The result of t-test analysis reveals that the value of $\mathrm{t}=3.842$ and $p=0.001(p<0.01)$. It is very significant. It means that there are significant differences before and after the trauma healing methods are given. In other words, there is effective influence in implementing trauma healing method to PTSD after the trauma healing methods are given because the level of PTSD is lower (M Post test $=37,96$ and M Pretest $=41.79$ ). Based on this result, it can be said that trauma healing methods are effective to reduce PTSD.

The result of t-test analysis i.e. the independent sample t-test in the experimental group and control group by using the gain score, shows that there are differences in the mean between the experimental group and the control group. The result of the t-test analysis reveals the value of $\mathrm{t}=1.925$ and $p=0.059$ (sig. 2-tailed), 0.0295 (sig 1-tailed) $(p<0.05)$. It is also significant. It means that the experimental group had a higher changes than the control group. The result of the average value (mean) in the experimental group shows the value of $\mathrm{M}=3.82$ and in the control group shows the value of $M=1.03$. Based on the analysis, it can be concluded that the mean between the experimental group and the control group is significant. It means that there are significant differences on PTSD between the experimental group and the control group. The rate of PTSD in experimental group is lower than the rate in the control group. Based on this, it can be said that the trauma healing is effective to reduce PTSD.

From both the results of the analysis, it can be concluded that the researchers' hypothesis that there is effectiveness on the use of trauma healing method to reduce post traumatic stress disorder, there are the different levels of Post-Traumatic Stress Disorder before and after the trauma healing methods are implemented and there are different levels of Post-Traumatic Stress Disorder between the experimental group and the control group can be proved.

\section{Discussion}

Disaster and post-disaster will leave severely bad memory for individuals who experience it. It often becomes a nightmare throughout the life, so that the incident likely to cause discomfort for those who experience 
it. Various pressures felt at post-disaster give psychological impact on the victim's condition. The psychological condition can be the feelings of trauma and post-traumatic stress. Trauma in terms of psychology refers to shocked and stressed conditions due to an event that stays relatively long in the victims. According to Taylor (2000) some of the conditions that can potentially be traumatic events are disaster, victims of crime, loss of loved ones (family, relatives, friends, etc.), and loss of property.

Parkinson (2000) explains that traumatic events can appear when the disaster occurs until the disaster has passed. The last condition is called PTSD. Based on this, it can be said that the long effect of the event of a disaster due to the eruption of Mount Merapi and the impact experienced by the survivors, left a deep impression on the memory of survivors. The impression will lead to new problems i.e. the emergence of psychological disorders such as fear, depression, trauma, stress and to the severe levels, such as PTSD . When those kinds of disorders are experienced in a long time it can interfere the ability of individuals in their activities so that it hinders productivity, or even the victims can no longer enjoy their life and tend to live in despair.

Trauma of post-disaster is a kind of PTSD as proposed by Nevid et al. (2005). PTSD is an ongoing maladaptive reaction to a traumatic experience or event. This type of disorder can be found in the survivors of Mount Merapi eruption. This research was conducted to teenagers (second grade of junior high school) with the consideration that trauma in children and teenagers has an impact on its development. Unresolved trauma can harm their psychology. Trauma occurs to children or teenagers which is not managed, makes them more vulnerable to risky behavior in their subsequent developments. Goleman (1999) mentions that many teenagers experience severe emotional problems such as irritable, easily distracted, desperate, difficult to control impulses, difficult to take decisions and motivate themselves. Some events experienced by teenagers will influence their development. It is in line with Rich, et al. (2009) who states that children and teenagers who have experienced the trauma in the past, tend to have negative or maladaptive behavior. When they become adult, they might have psychological and emotional disorders, sexual disorders, be alcoholics, and do domestic violence or have social disorder relationship.

From the results of this study, it can be concluded that teenagers in the location where the study was carried out still have memories that disturb their mind, although Merapi disaster has passed. The individuals feel that they reexperience the traumatic event in their mind (intrusive re-experiencing), avoid objects reminiscent of the trauma (avoidance) and have awareness or excessive vigilance (hyper-arousal). These kinds of feelings appear in such phenomena like being restless, agitated, unable to sleep, difficult to concentrate, daydreaming, irritable, angry, introvert, inferior, and many others. All of these can occur due to many students as the participants of the study live in the slope of mount Merapi and they experienced directly the catastrophic events of the volcano. For several months, they were evacuated in the shelters so that they did not go to school. Being panic, lifestyle changes, fears, and anxiety give bad memories and trauma. This is in line with Arfianti's research (2011). She says that although the disaster has passed for a year but trauma still experienced by most children.

Based on the research on the level of psychological distress of students of SDN (elementary school) 02 Terandam, Eastern District of Padang in 2011 conducted by Arfianti (2011) one year after the post trauma healing due to the earthquake, it was obtained that there is cognitive symptom of psychological distress such as crying or whining $(97.5 \%)$, incapability of concentrating on studies $(68.75 \%)$, somatic symptom of psychological distress such as abdominal pain $(92.5 \%)$, fatigue (90\%), and headache (87.5\%), and emotional symptom of psychological distress such as concerning about the safety of their beloved relatives (95\%), feeling sad (91.25\%), and feeling scared of the next earthquake (86.25\%). A random sample of Americans, shows that $72 \%$ reported that they have deal with traumatic experiences such as natural disasters, death of a child, serious car accident, being a witness of violence, or experiencing physical assault, rape, or physical or sexual abuse (Elliot \& Church, 1997). Researchers believe that about 8\% of American adults experience PTSD at some points in their lives (Kessler et al., 1995).

Trauma healing is an activity or action to reduce and eliminate as well as help others who experience 
The effectiveness of trauma healing methods to reduce PTSD on teenage victims of Mount Merapi eruption

psychological disturbances due to shock or trauma. The purpose of this method is to help the subjects reduce the symptoms of post-traumatic stress disorder. Subjects are guided to do such techniques that help the process of healing post-traumatic stress so that they are not affected by the symptoms and wounds caused by trauma. Based on the previous description, it can be concluded that trauma healing methods are effective to reduce the level of Post-Traumatic Stress Disorder.

The result of the analysis shows that there is effective influence of delivering trauma healing methods to reduce PTSD. The effectiveness of the methods is likely because of the selection of the methods which are simple and easy to be followed by the subjects of the research. The success of declining the rate of the trauma could be because the implementation was carried out in such atmosphere such as the location chosen - in the mosque behind the school which was closed and comfortable - so that it was not distracted by other students who were not the subjects of the study or other external factor. Besides, there are also other factors such as the support from the principal and teachers, experienced facilitators, and the selection of Javanese musical instrument.

Javanese musical instrument was selected because it is very familiar to the majority of Yogyakarta citizens, calm, and contains elements of the local culture. Local beliefs as well as local cultural elements are important in self-healing. It is in line with research held by Quinn (2007) which states that local culture helps overcome the trauma of Aborigins and their children because of colonization to them. Based on the evaluation of the participants, the tutors in general could deliver the materials effectively so that the participants understood the materials given. Tutors are very important part in determining the success and the effectiveness of training (Ancok, 2007; As'adi, 2009). The selection of trauma healing methods proves that it gives influence in decreasing the level of trauma. The subjects of the research were students (early teens), so if the methods used had been complicated they might not have been able to join and would have got bored. Therefore, the methods implemented were easy, interesting and could be done by anyone. Trauma healing methods used in this study are visualization, Pal and Gum, Tai Chi, accupressure, and massaging accompanying with Javanese traditional music.

Visualization method is done through movement and hand touching to listen to our body. In our stress and difficulties of this life, if we have the ability to nurture ourselves we would be calm and it can relax the soul and body. Listening to our body means learning to feel what is happening at the moment. This method is useful because if we understand ourselves, our gratitude to God will appear. Psychologically, our mind and soul will be calm. Pal and Gum is an exercise to balance and enhance our body's energy and to eliminate tension. It is very useful and appropriate for individuals who get stressed due to trauma. Tai Chi is a method to heal stress and trauma that brings balance and harmony of body, mind and spirit. Tai Chi is able to build stamina and strength which is often lost in individuals who experience trauma.

Acupressure method uses finger pressure on specific points to open life energy blockages in our body. The research reveals that accupressure can help effectively lose the symptoms of stress caused by trauma such as restlessness, anxiety, insomnia, abdominal pain, headache, pain all over the body. Acupressure points can be used when the symptoms of trauma and stress appear. When it is practiced every day it can maintain smooth flow and the balance of energy to the entire body to prevent the symptoms of stress. One of the effects of stress due to trauma is having strong feeling or emotion. It flows through our body in such feeling like being afraid, angry, anxious, sad etc. How to cope with raging emotion is by recognizing it and doing such activities to free the blockage of energy from emotion. One way to release energy blockages and to balance the energy from the raging emotion is by having massage techniques on fingers, shoulders, neck, head, etc. Massage stimulates the energy to flow smoothly and healthily and balances all the systems in the body.

The weaknesses of this study are (1) the training did not run as scheduled. It was due to the other activities which were also held at school. Follow-up measurement could not be conducted to see the effects of trauma healing methods in the long term because of the limited time given by the school. 


\section{Conclusions}

Based on the conducted analysis it can be concluded that there is effective use of trauma healing methods in reducing post trauma traumatic stress disorder (ADHD). It is indicated by the different levels of post-traumatic stress disorder both before and after the trauma healing methods are given and the difference between experimental group and control group. The researchers recommended some suggestions as follows: the results show that the method given i.e. Trauma healing can help decrease the level of post-traumatic stress disorder of the students. Thus, it is recommended as an alternative way to handle individuals who have sustained trauma. For other researchers who are interested to conduct further research on the same theme, it is advisable to have a follow-up measurement in order to see the effect of trauma healing methods in the long term. For further research, the provision of treatment should be implemented in longer time or more meetings in order to gain more effective results in reducing post-traumatic stress disorder and can be implemented to different participants due to their age.

\subsection{Implications}

The implications of this study for students and teachers is a method of trauma healing role in providing skills in trauma healing methods practiced on the teachers and students and can help to reduce post-traumatic stress disorder experienced by the students victims of Mount Merapi eruption.

\section{References:}

Afrianti, M. (2011). The level of psychological distress one year after the earthquake due to trauma healing in class III, IV, and V SDN 02 in Terandam sub-district East Padang, Padang 2011. Research Report. Nursing Faculty of Andalas University, Padang.

American Psyciatric Association. (1994). Diagnostic and statistical manual of mental disorder (4th ed.).Washington DC.

Ancok, D. (2007). Outbound management training: Application of behavioral science in human resource development. Yogyakarta: UII Press.

Andayani, T. T. (2011). Public donation fund for economic development of post-disaster trim. Journal of Disaster Management, 2(1), 41- 49.

Arikunto. (2010). Procedure research a practical approach. Jakarta: Rineka Cipta.

As'adi, M. (2009). The power of outbound training. Yogyakarta: Power Books.

Boulware, E. (1999). Do I have anxiety. Retrieved July 15, 2012, from http://www.sidran.com

Bryant, R. A., Harvey, A. G., Guthrie, R. M., \& Moulds, M. L. (2000). A prospective study of psychophysiological arousal, acute stress disorder, and posttraumatic stress disorder. Journal of Abnormal Psychology, 109, 341-344. http://dx.doi.org/10.1037/0021-843X.109.2.341

Cane, P. M. (2011). CAPACITAR: Trauma recovery and transformation. YABES Foundation.

Durand, V. M, \& Barlow, D. H. (2006). Abnormal psychology (4th ed.). Translators: H. P. Soetjipto dan S. M. Soedtjipto. Yogyakarta: Pustaka Pelajar.

Elliot, A. J., \& Church, M. A. (1997). A hierarchical model of approach and avoidance achievement motivation. Journal of Personality and Social Psychology, 72, 218-232. http://dx.doi.org/10.1037/0022-3514.72.1.218

Flannery, R. B. (1999). Psychological trauma in post-traumatic stress disorder: A review. International Journal of Emergency Mental Health, 1(2), 77-82.

Foa, E. B., Davidson, J. R. T., \& Frances, A. (Eds.). (1999). The expert consensus guideline series: Treatment of Post-Traumatic Stress Disorder. The Journal of Clinical Psychiatry, 60(16), 3-76.

Foa, E. B., Keane, T. M., \& Friedman, M. J. (2000). Guidelines for treatment of PTSD. Journal of Traumatic Stress, 13(4), 539-588. http://dx.doi.org/10.1023/A:1007802031411

Foa, E. B., Rothman, B. O., Riggs, D. S., \& Murdock, R. B. (1991). Treatment of posttraumatic stress disorder in 
The effectiveness of trauma healing methods to reduce PTSD on teenage victims of Mount Merapi eruption

rape victims: A comparison between cognitive-behavioral procedures and counseling. Journal of

Consulting and Clinical Psychology, 59(5), 715-723. http://dx.doi.org/10.1037/0022-006X.59.5.715

Goleman, D. (1999). Emotional intelligence to achieve peak performance. Translators: Widodo, A.T.K. Jakarta:

Gramedia Pustaka Utama.

Heights, C., \& Chicote, R. L. (2007). Art therapy with child tsunami survivors in Sri Lanka. Art Therapy:

Journal of America Art Therapy Association, 24(4), 156-162.

http://dx.doi.org/10.1080/07421656.2007.10129475

Kaplan, H. I., \& Sadock, B. J. (1997). Synopsis of psychiatry (7th ed.). Jakarta: Binapura Aksara.

Kessler, R. C., Sonnega, A., Bromet, E., Hughes, M., \& Nelson, C. B. (1995). Posttraumatic stress disorder in the National Comorbidity Survey. Archives of General Psychiatry, 52, 1048-1060. http://dx.doi.org/10.1001/archpsyc.1995.03950240066012

Mayers, A., \& Hansen C. H. (2002). Experimental psychology (4th ed.). New York: Wadsworth Thomas Learning.

Nevid, J. S., Rathus, S.A., \& Greene, B. (2005). Abnormal psychology. Translators: Team Faculty of Psychology, University of Indonesia. Jakarta: Erlangga.

Direktorat Jenderal Pelayanan Medik. (1993). Guidelines for the classification and diagnosis of mental disorder in Indonesia III (PPDGJ III). Jakarta: Departemen Kesehatan RI.

Parkinson, F. (2000). Post trauma stress: A personal guide to reduce the long-term effects and hidden damage caused by violence and disarter. Fisher Book.

Paton, J. (2009). Young offenders' experiences of traumatic life events: A qualitative investigation. Clinical Child Psychology and Psychiatry, 14(1), 43-62. http://dx.doi.org/10.1177/1359104508100135

Quinn, A. (2007). Reflection on intergenerational Trauma: Healing as a critical itervention. First People Child \& Family Review, 3(4), 72-82.

Ranimpi, Y. Y. (2003). Social conflict and PTSD: A theoretical approach. Indonesian Journal of Psychology Anima, 18(2), 171-178.

Rich, M., Corbin, B., Rich, L., \& Evans, W. (2009). Healing the hurt: Trauma-informed approaches to the health of boys and young man of color. School of Public Health. Drexel University College of Medicine. Funded by: The California Endowment.

Rothschild, B., (2000). The body remembers: The psychophysiology of trauma and trauma treatment. New York: W.W. Norton \& Company.

Schiraldi, G. R. (2009). The Post-Traumatic Stress Disorder sourcebook (2th ed.). New York: Mc Grow Hill.

Seniati, L., Yulianto, A., \& Setiadi, B. (2011). Psychology experiments. Jakarta: PT. Indeks.

Taylor, S. E. (2000). Health psychology (3rd ed.). McGraw-Hill International.

Terr, L. C. (1988). What happens to memories of trauma? A study of twenty children under five at the time of documented traumatic events. Journal of the American Academy of Child \& Adolescent Psychiatry, 27, 96-104. http://dx.doi.org/10.1097/00004583-198801000-00015

The Sidran Institute. (2003). What is Post-Traumatic Stress Disorder? Retrieved July 11, 2012, from http://www.sidran.com

The Sidran Institute. (2003). What is psychological trauma? Retrieved January 15, 2012, from http://www.sidran.com

Van Etten, M. L., \& Taylor, S. (1998). Comparative efficacy of treatments of posttraumatic Stress Disorder: A meta-analysis. Clinical Psychology \& Psychotherapy, 5, 125-144. http://dx.doi.org/10.1002/(SICI)1099-0879(199809)5:3<126::AID-CPP153>3.0.CO;2-H

Zlotnick, C., Johnson, S., Miller I., Howard M., \& Pearlstein, T. (2001). Postpartum depression in women on public assistance: Pilot study of an interpersonally-oriented group. American Journal of Psychiatry, 158, 638-640. http://dx.doi.org/10.1176/appi.ajp.158.4.638 
Tentama, F., Mulasari, S. A., Sukesi, T. W., \& Haryono, W. 